\title{
Continuing medical education: consultant psychiatrists' experiences and opinions
}

\author{
Tom Sensky
}

\begin{abstract}
A representative sample of 307 consultant psychlatrists was canvassed regarding experiences and views of continuing medical education (CME). Full responses were recelved from 73\%. The results incicated that most respondents already particlpated in a range of CME activities, inclucling attendance at local and other educational meetings, and teaching. Those respondents who had fow consultant peers, or who did not teach poychiatilic trainees or medical students, also participated in fower CME activities. Nearty hall the sample funded their CME activitios wholly or in part from their own pockets. The majortty of respondents supported some form of speclallst accediation based on participation in CME.
\end{abstract}

The setting up in 1992 of the College's Special Committee on Continuing Medical Education represented an acknowledgement of the particular importance of continuing medical education (CME)-education and training aimed specifically to meet the needs of consultants and other psychiatrists not in training grades. An essential component of the committee's remit is to make recommendations on the development of CME for psychiatrists. To help in this task, the committee undertook a survey of consultants' experience of, and opinions about, CME.

The questionnaire used in this survey, based on one used in an earlier survey by the Royal College of Obstetricians and Gynaecologists (Royal College of Obstetricians and Gynaecologists, 1991), went through several revisions in the hands of the committee. It was then plloted using members of Council as a trial group, and modified further in the light of the results. The following topics were covered: sociodemographic details; details of respondents' post and work setting; resources avallable for CME; respondents' teaching activities; avallability of and attendance at CME activities; facilities for study leave; views on a range of specific CME activities; views about mailing lists of Members and Fellows; and views about mandatory CME and accreditation.

\section{The survey}

The questionnaire was sent in November 1992 to a random sample of 307 Members and Fellows of the College (a 1:10 sample) who were consultant psychiatrists. By the end of May 1993, 243 responses (79\%) had been received. However, 18 respondents filled in very few detalls. The results presented are therefore based on 225 responses (73\%).

In addition to analysing the responses of the sample as a whole, analyses were also undertaken with the sample divided according to main specialty, numbers of consultant colleagues, whether or not respondents taught psychiatric trainees or medical students, whether or not they worked on a single or split sites, and whether or not they had responsibilities beyond their own health districts. The sub-groups thus generated were compared using $\chi^{2}$ tests or one-way analysis of variance, as appropriate.

\section{The sample}

Of the 225 respondents providing data, 46 (20\%) were female and 64 (28\%) were Fellows. The mean age of the sample was 48 years. Only two respondents were not currently working in psychiatry. The majority worked in general adult psychiatry $(n=131,58 \%)$. Forty-one respondents $(18 \%)$ worked in child and adolescent psychiatry, and $38(17 \%)$ in old age psychiatry. Other specialties were less frequently represented.

Using data collected by the College, it was possible to compare those who responded to the questionnaire with non-responders. There was a higher proportion of retired Members and Fellows among the latter. Excluding those who had retired, there were no significant differences between non-responders and those who did respond in mean age, sex, main specialty or health region.

Of the respondents, $183(88 \%)$ currently had an NHS contract, and $63(31 \%)$ had either full or honorary academic contracts. Most worked 
Table 1. Percentage of respondents with access to educational resources

\begin{tabular}{lll}
\hline Resource & $\begin{array}{l}\text { \% Total sample } \\
(n=225)\end{array}$ & $\begin{array}{l}\text { \% Respondents } \\
\text { who do not teach } \\
\text { trainees } \\
(n=29)\end{array}$ \\
\hline Slide projector & & $65^{*}$ \\
Overhead projector & 83 & $69^{* *}$ \\
Video recorder & 95 & $62^{*}$ \\
Photocopler & 80 & $76^{* *}$ \\
One-way mirror & 96 & 28 \\
Computing facilities & 38 & 48 \\
Literature search facility & 56 & 41 \\
Department of Medical illustration & 69 & 34 \\
\hline
\end{tabular}

${ }^{*} P<0.02 ; " * P<0.0001$.

full-time ( $n=166 ; 80 \%)$. One hundred and fiftyfour $(68 \%)$ worked on more than one site. Fourteen (8\%) had no consultant colleagues in their unit, and a further 21 (9\%) shared their unit with only one consultant colleague.

One hundred and forty-one respondents (63\%) reported that they had responsibilities beyond the health district in which they were based. Most ( $n=200 ; 89 \%$ ) had on-call duties. Twentyone respondents $(9 \%)$ reported on-call rotas of $1: 1$ or $1: 2$. More than half $(53 \%)$ had rotas less onerous than $1: 4$, and $25 \%$ reported rotas of $1: 8$ or less. All but 17 respondents saw out-patients, but $60(29 \%)$ did not have any in-patient admissions.

\section{Findings}

\section{Educational resources}

Of the eight specific resources inquired about in the survey (see Table 1), $74 \%$ of the respondents had six or more avallable to them. The avallability of these resources was significantly associated with teaching psychiatric trainees or medical students.

A library was avallable at their main work site to 156 respondents (69\%). Of those respondents who had fewer than two consultant colleagues, only $47 \%$ had access to a library at the main site of work, compared with $75 \%$ of the remaining respondents $(P=0.002)$. In general, there were only a limited number of psychiatric journals at the library most accessible to each respondent 10 journals or less in 132 cases (59\%). In only 42 cases (19\%) did the local library contain more than 15 psychiatric journals. Most respondents were able to order books on inter-library loan $(n=206 ; 92 \%)$ and in 152 cases $(68 \%)$, such loans were free of charge. For only 17 respondents were loans more costly than $£ 1$ each. In most instances (78\%), the cost of such loans was met by respondents.
Most respondents visited their library at least once a month ( $n=173 ; 77 \%)$, half of these making at least one visit weekly. The majority of respondents reported looking at every issue of The British Journal of Psychiatry ( $n=159 ; 71 \%)$ and the Psychiatric Bulletin ( $n=146 ; 65 \%)$. Thirtythree respondents (15\% of the sample) subscribed to at least one journal, and $24 \%$ subscribed to more than one. One hundred and seventeen respondents read every issue of at least one journal. There was no association between subscribing to one or more journals and ease of access to a library.

\section{Teaching activities}

Only 12 respondents (5\%) did no regular teaching of any kind. One hundred and twenty one (54\%) were involved in regular teaching for medical students. All but 29 (13\%) regularly taught junior staff. Child and adolescent psychiatrists were significantly less likely than the other respondents to be involved in regular teaching of trainee psychiatrists $(41 \%$ v. 91\%; $P<0.0005)$. Lack of teaching responsibilities was associated with less frequent attendance at educational meetings, both locally and further afield (Table 2 ).

\section{Attendance at educational meetings}

Of the types of meeting enquired about in the survey (Table 2), 11 respondents $(5 \%)$ did not report attending any, while $60 \%$ reported attending four or more types of meeting.

Only 13 respondents $(7 \%)$ reported that outside guest speakers were never invited to their district, although in 40 cases ( $18 \%$ ), guest speakers were never invited to the respondent's unit. Outside guest speakers came at least once each academic term to the respondent's district in $59 \%$ of cases, and to their unit in $48 \%$ of cases.

Fifty-eight respondents (26\%) had attended no College meetings of any type in the preceding 
ORIGINAL PAPERS

Table 2. Attendance at meetings of different types

\begin{tabular}{|c|c|c|}
\hline Type of meeling & $\begin{array}{l}\text { \% Total somple } \\
(n=225)\end{array}$ & $\begin{array}{l}\text { \% Respondents } \\
\text { who do not teach } \\
\text { trainees } \\
(n=29)\end{array}$ \\
\hline $\begin{array}{l}\text { Local audit meeting } \\
\text { Local journal club } \\
\text { Local case conference } \\
\text { Any local meeting } \\
\text { College Quarterty/Annual } \\
\text { College divisional } \\
\text { College sectional/Special Interest } \\
\text { Any type of College meeting } \\
\text { National/international specialist } \\
\text { Research society } \\
\text { Pharmaceutical company sponsored } \\
\text { Any type of non-College meeting }\end{array}$ & $\begin{array}{l}88 \\
60 \\
83 \\
95 \\
43 \\
38 \\
51 \\
74 \\
53 \\
21 \\
58 \\
76\end{array}$ & $\begin{array}{l}55^{* *} \\
24^{* *} \\
48^{* *} \\
69^{* *} \\
34 \\
24 \\
48 \\
59 \\
45 \\
7 \\
38^{*} \\
59^{*}\end{array}$ \\
\hline
\end{tabular}

12 months, while 93 respondents (41\%) had attended two or three different types of College meetings. Fifty-six respondents (24\%) had attended no non-College meetings, while 95 (42\%) had attended two or more types of non-College meetings. Among the specialties, child and adolescent psychiatrists differed from their colleagues in attending College sectional meetings more frequently $(79 \%$ v. $40 \% ; P<0.0001)$ but being less likely to attend any type of local meeting (53\% v. 98\%; P<0.0001). Those respondents with fewer than two consultant colleagues were less likely than others to regularly attend meetings, both locally and elsewhere. For example. of the former group, only $83 \%$ attended audit meetings, and only $55 \%$ attended any nonCollege meetings, compared with $95 \%$ and $79 \%$ respectively for respondents with two or more consultant colleagues.

The majority of respondents $(n=166 ; 74 \%)$ preferred educational activities covering half a day. while $122(54 \%)$ preferred lunchtime meetings. Less popular options were full day meetings (endorsed by $28 \%$ ), evening meetings (19\%) and those lasting more than one day $(6 \%)$.

Asked to choose from a list of six possible reasons for not attending meetings, most respondents cited the venue $(n=145 ; 64 \%)$ and timing $(n=147 ; 65 \%)$, while content was cited by 141 respondents (63\%). Inadequate consultant cover was endorsed by 95 respondents (42\%), and 66 (29\%) indicated low levels of staffing at trainee level as a reason. Only 29 respondents (13\%) cited fallure to get paid study leave as a reason (although many respondents met their expenses from their own pockets). Only nine respondents
(4\%) indicated that paid locums were provided to allow them to take study leave.

\section{Funding of study leave}

Seventy-five per cent of the respondents funded their study leave from more than one source. Thirty-seven (18\%) had their entire study leave paid for out of a specific study leave budget, not shared with trainees or colleagues of other disciplines. Overall, more than $70 \%$ of the respondents received at least some of their funding from a specific study leave budget. Of those respondents with fewer than two consultant colleagues, only $39 \%$ had access to a specific study leave budget, compared with $79 \%$ of the remaining respondents $(P<0.0001)$. Compared with other respondents, child and adolescent psychiatrists were also less likely to have access to a specific study leave budget (23\% v. $76 \%$; $P<0.0005)$. Forty-three per cent of the sample $(n=97)$ contributed to their study leave out of their own pockets, and $36 \%(n=81)$ reported receiving contributions from drug companies.

\section{Opinions on accreditation}

The majority of respondents ( $n=116 ; 52 \%)$ endorsed the view that CME should be mandatory, and 57\% $(n=130)$ considered that there should be regular formal assessment of participation in CME. Fifty-seven per cent of respondents considered that $\mathrm{CME}$ assessment should be mandatory for psychiatric trainers, and an equal number said that satisfactory CME assessment should be a prerequisite for specialist registration with the General Medical Council. 


\section{Comment}

The high response rate, together with the similarities between respondents and nonrespondents in age, sex, specialty and type of post, allows the results to be considered as representative of consultant psychiatrist Members and Fellows as a whole. However, it is important to note that the sample was not of all career psychiatrists. There are others who require CME whose views were not canvassed, e.g. clinical assistants, staff grade doctors, psychiatrists working in the pharmaceutical industry, etc.

Although the $5 \%$ of respondents who did not regularly attend any local meetings represent a small minority, this should nevertheless be one focus for further attention - to identify why this group does not attend meetings, and work towards supporting their needs. Compared with the rest of the sample, those 42 respondents (19\% of the total respondents) who attended fewer than three types of local meeting were also less likely to do any teaching, to attend any type of College meeting, and to regularly attend more than one type of non-College meeting. It would thus appear that those who do not engage in CME activities locally (for whatever reason), are also less likely to take advantage of existing educational opportunities elsewhere, either at College meetings or others.

The survey has also identified some groups of consultants who do not fare as well as others in their educational activities. These include consultants with few peers, and those who do little teaching either of junior medical staff or medical students. There were considerable overlaps between these groups. Among those who did not teach trainees regularly, 10 of 29 (34\%) had no consultant colleagues, and a further four had only one colleague. Thus $48 \%$ of this group were either single-handed, or had only one consultant colleague, compared with only $12 \%$ of the remainder of the sample. Similarly, of the 29 respondents who did not teach psychiatric trainees, only seven (24\%) taught medical students. This compares with $54 \%$ of the whole sample involved in medical student teaching. However, most of those who did not teach medical students did teach trainees (79\%). In each of these groups, the results of the survey do not offer a complete explanation for their infrequent participation in CME activities. However, the survey suggests that such groups of consultants are likely to have particular needs which will have to be met before they are able to take better advantage of CME.

The results indicate that although child and adolescent psychiatrists do less local teaching than consultants of other specialties and attend fewer local meetings, they are more likely than other psychiatrists to attend College section meetings. Very few other significant differences emerged when comparing each specialty with the remainder of the sample. One exception was the finding that general adult psychiatrists were much less likely than the remainder of the sample to attend non-College meetings - only $19 \%$ attended two or more types of non-College meetings in the 12 months before the survey, compared with $51 \%$ of the other respondents $(P<0.0001)$.

No differences emerged between those who attended meetings and those who did not in terms of the reasons for non-attendance. In particular, the fallure to get locums, or to get paid study leave, were both infrequent reasons for nonattendance at meetings, although it must also be remembered that the majority of respondents used their own funds (either alone, or supplemented by others) to pay for their study leave.

Overall, the responses indicated that consultant psychiatrists already participate in continuing education to a considerable degree in terms of their attendance at local meetings, and also in their teaching activities. Attitudes to CME were positive, with the majority of respondents endorsing the view that it should be mandatory, and that it should involve formal assessment.

Most of these results, regarding both experience of CME and attitudes to accreditation, are remarkably similar to those reported in the survey of obstetricians and gynaecologists (Royal College of Obstetricians and Gynaecologists, 1991). One important difference was that unlike psychiatrists, gynaecologists frequently cited failure to get locum cover as a reason for not attending educational activities.

It is hoped that the results of this survey will inform further discussions on the development of CME both within and beyond the College.

\section{Acknowledgements}

All the members of the Special Committee on CME contributed to the development of the questionnaire and the discussion about its results. The survey owes much to Lynette Napper, the College's Education Officer until her recent death; she was very much involved in the development of the questionnaire and its administration. Miss Debi Davidson kindly helped in collecting data for analysis.

\section{Reference}

Royal Cousge of Obstetricuns and Gnnacologists (1991) Report of the RCOG Working Party on Continuing Medical Education. June 1991.

Tom Sensky, Special Committee on Continuing Medical Education. The Royal College of Psychitatrists 